\title{
Effect of Salt on Growth of Rice Landraces in Vietnam
}

\author{
L.H. Anh ${ }^{1}$, H.T.Hue ${ }^{2}$, N.K.Quoc ${ }^{2}$, L.T.Nghia ${ }^{2}$, K.H. Trung ${ }^{3}$, T.N.Trung ${ }^{4}$, \\ D.H.Trang ${ }^{3}$, T.D.Xuan ${ }^{1, a^{*}}$ and T.D.Khanh ${ }^{3, b^{*}}$ \\ ${ }^{1}$ Department of Development Technology, Graduate School for International Development \\ and Cooperation (IDEC), Hiroshima University, Japan \\ ${ }^{2}$ Plant Genetic Resource, Vietnam \\ ${ }^{3}$ Agricultural Genetics Institute, Tuliem, Hanoi, Vietnam \\ ${ }^{4}$ Bio-Agriculture Institute, Haiphong University, Hanoi, Vietnam \\ a tdxuan@hiroshima-u.ac.jp; ${ }^{b}$ tdkhanh@vaas.vn; tel + 84-916-451-018
}

Keywords: Rice, Gene/QTL, salinity tolerance, landrace, variety.

\begin{abstract}
In this study, total 41 Vietnamese rice landraces were evaluated for their salt tolerance in the laboratory and field conditions. Amongst them, 15 landraces have shown moderate to high salinity tolerance in both screening conditions. The three landraces Chanh trui, Cuom dang 2 and Nep cuc have revealed the highest salt tolerance which were similar to the Pokkali. However, with time and levels of salt treatments, salt injury symptoms were clearly observed in all landraces with different symptoms. All plants growth parameters were remarkably reduced in all landraces under increasing salt-treated concentrations. By use of molecular marker RM217 linked with salinity tolerance QTL located on the chromosome 4, 11 landraces have been found to carry the allen involving in salt tolerance. This study has provided useful information on salinity tolerance of rice landraces for breeding programs to deal with the climate change in this country.
\end{abstract}

\section{Introduction}

Vietnam is an agriculture country where is known to be rich in rice diversity germplasm. Rice landraces are very diversified and played an important role in rice breeding for sustainable agriculture production in this country $[1,2]$. Numberous rice landraces such as native and local rice landraces have had high values of agronomical traits such as tolerance of abiotic and biotic stresses which are well grown in wide ranges and adapted under the adversely environmental conditions [3]. Among abiotic stresses, the salt tolerance in rice is considered as one of the most important traits to deal with the adverse effects from climate change in this country [4]. Salinity is a main abiotic stress constraining yields of crops in many areas in the world, of which 800 million hectares worldwide, equivelent with $6 \%$ of earth land are being influenced by salt, $20 \%$ out of 230 million hectares of irrigated regions have seriously affected salt intrusion [5, 6]. Vietnam, with $3260 \mathrm{~km}$ of coastline where there are two biggest low-lying rice deltas (Red River and Mekong Deltas) are being influenced by detrimental effects from climate change, caused most serious in agricultural production due to mainly through sea levels rise and unexpected rainfall intensity and temperatures [7]. A large rice growing areas in this country is affected with salinity intrusion over 1 million ha, equally with $3 \%$ of total Vietnam area $[4,8]$, causing the economic loss by salt intrusion in 2005 was up to 45 million USD, which is equivalent to $1.5 \%$ of annual rice productivity in the Mekong delta. To date, approximately 600.000 ha is being severely affected by drought and saline intrusion in the early year of 2016 , caused economic losses up to 15 trillion VND $(\approx 670$ million USD) [9]. It has a salinity threshold of $3 \mathrm{dS} / \mathrm{m}$, with a $12 \%$ reduction in yield per $\mathrm{dS} / \mathrm{m}$, beyond this threshold. Therefore, rice yields can be reduced by up to $50 \%$ when grown under moderate $(6 \mathrm{dS} / \mathrm{m})$ salinity levels [10].

Rice (Oryza sativa L.) is one of the most important cash crops in Vietnam, providing daily food for more than 90 million people in this country. The productivity of the commercial rice varieties have been significantly reduced when growing under the affected-salt areas. Some local rice landraces are being grown in coastal areas with high salt intrusion up to several hundreds of 
hectares. They have shown very high salt tolerance potential which are the good sources should be developed and exploited [8]. Therefore, the objectives of this study were to evaluate the salinity tolerance ability of some Vietnamese rice landraces in both laboratory and field conditions. Further confirmation of salinity tolerance of those landraces by the use of SSR marker linked with QTL/gene salinity tolerance qSTR-4-CK was also made.

\section{Materials and Methods}

\section{Plant Materials}

Total 41 Vietnamese rice landraces (varieties) were collected from some different growing areas in 2014 as shown in Table 1. IR28 (salt sensitive), while Pokkali (high salt tolerance) varieties were used as the controls.

Table 1. List of the local rice landraces were used to evaluate ability of salt tolerance

\begin{tabular}{|c|c|c|c|c|}
\hline No & Name of rice landrace & Origin/Province & Gene bank & Growing areas \\
\hline 1 & Bac thom 7 & Imported & PRC & RRD \\
\hline 2 & Nuoc man Hue & Thua Thien Hue & PRC & $\mathrm{CD}$ \\
\hline 3 & Nuoc man dang 1 & Quang Tri & PRC & $\mathrm{CD}$ \\
\hline 4 & Hau trang & Thua Thien Hue & PRC & $\mathrm{CD}$ \\
\hline 5 & Lua do & Thua Thien Hue & PRC & $\mathrm{CD}$ \\
\hline 6 & Lua su dang 1 & Quang Binh & PRC & $\mathrm{CD}$ \\
\hline 7 & Lua ven dang 1 & Quang Binh & PRC & $\mathrm{CD}$ \\
\hline 8 & Te cham & Quang Binh & PRC & $\mathrm{CD}$ \\
\hline 9 & Quang trang & Quang Tri & PRC & $\mathrm{CD}$ \\
\hline 10 & Ven do & Quang Tri & PRC & $\mathrm{CD}$ \\
\hline 11 & Nuoc man Quang Tri & Quang Tri & PRC & $\mathrm{CD}$ \\
\hline 12 & Lua ngoi & Thanh Hoa & PRC & $\mathrm{CD}$ \\
\hline 13 & Lua cham & Nam Dinh & PRC & $\mathrm{CD}$ \\
\hline 14 & Hom rau 1 & Thai Binh & PRC & $\mathrm{CD}$ \\
\hline 15 & Hom rau 2 & Thai Binh & PRC & $\mathrm{CD}$ \\
\hline 16 & Cuom dang 1 & Nam Dinh & PRC & $\mathrm{CD}$ \\
\hline 17 & Cuom dang 2 & Nam Dinh & PRC & $\mathrm{CD}$ \\
\hline 18 & Chiem rong & Nam Dinh & PRC & $\mathrm{CD}$ \\
\hline 19 & Ngoi tia & Nam Dịnh & PRC & $\mathrm{CD}$ \\
\hline 20 & Nep cuc & Ninh Binh & PRC & $\mathrm{CD}$ \\
\hline 21 & Lua cham bien & Ninh Binh & PRC & $\mathrm{CD}$ \\
\hline 22 & Re trang & Hai Phong & PRC & $\mathrm{CD}$ \\
\hline 23 & Nep quan & Hai Phong & PRC & $\mathrm{CD}$ \\
\hline 24 & Manh re & Quang Binh & PRC & $\mathrm{CD}$ \\
\hline 25 & Chiem cu & Quang Binh & PRC & $\mathrm{CD}$ \\
\hline 26 & Bau Hai Phong & Hai Phong & PRC & $\mathrm{CD}$ \\
\hline 27 & Nep chan & Nghe An & PRC & $\mathrm{CD}$ \\
\hline 28 & Te tep & Nam Dinh & PRC & $\mathrm{CD}$ \\
\hline 29 & On & Nam Dinh & PRC & $\mathrm{CD}$ \\
\hline 30 & Du Thanh Hoa & Thanh Hoa & PRC & $\mathrm{CD}$ \\
\hline 31 & Ven lun Thanh Hoa & Thanh Hoa & PRC & $\mathrm{CD}$ \\
\hline 32 & Tam lun & Hai Phong & PRC & $\mathrm{CD}$ \\
\hline 33 & Te Thom Lao Cai & Lao Cai & PRC & UA \\
\hline 34 & Tam Thom & Nam Dinh & PRC & $\mathrm{CD}$ \\
\hline 35 & Chiem tia chan & Hai Phong & PRC & $\mathrm{CD}$ \\
\hline 36 & Du Thom & Nam Dinh & PRC & $\mathrm{CD}$ \\
\hline
\end{tabular}




\begin{tabular}{|c|l|l|c|c|}
\hline No & Name of rice landrace & Origin/Province & Gene bank & Growing areas \\
\hline 37 & Loc Nghe An & Nghe An & PRC & CD \\
\hline 38 & Tam Nong & Nghe An & PRC & CD \\
\hline 39 & Nep rau & Thai Binh & PRC & CD \\
\hline 40 & Chanh trui & Thanh Hoa & PRC & CD \\
\hline 41 & Khang dan 18 & Imported & PRC & RRD \\
\hline 42 & Pokkali (salt tolerance) & Improrted & PRC & - \\
\hline 43 & IR28 (salt sensitive) & Imported & PRC & - \\
\hline
\end{tabular}

PRC: Plant Genetic Resource Center, Vietnam; RRD: Red River Delta; CD: Coastal Delta; ULA: Upland area; (-): unknown

\section{Evaluation of salt tolerance in the laboratory condition}

All collected landraces were screened to evaluate salinity tolerance following the method of IRRI [11]. The experiment were conducted at the Division of Molecular Biology, Plant Genetic Resources (PRC) in April, 2015. The pre-germinated seeds of each landrace were sown in the separate holes on Styrofoam floats of a net bottom suspended on trays and filled with Yoshida nutrient solution. Three replications were randomly generated with each experiment with at least 9 individual plants per line to evaluate for each replication of three treatments: $0 \mathrm{dS} / \mathrm{m}, 6 \mathrm{dS} / \mathrm{m}$ and 16 $\mathrm{dS} / \mathrm{m}$ of salt stress were imposed after $48 \mathrm{~h}$ of sowing by adding $\mathrm{NaCl}$ to an $\mathrm{EC}$ of $6 \mathrm{dS} / \mathrm{m}$ and $16 \mathrm{dS} / \mathrm{m}$ in Yoshida nutrient solution. IR28 (salt sensitive) and Pokkali (highly salt tolerant) varieties were used as the controls. The $\mathrm{pH}$ of the nutrient solution was daily adjusted to 5.0 and the culture solution was replaced every 2 days.

Salinity tolerance ability and the visual symptoms of landraces were evaluated at 7 days, 14 days and 21 days following IRRI's Standard Evaluation Score (SES) for rice, with the rating from 1 (highly tolerant) to 9 (highly sensitive). The main growth parameters included the shoot and root lengths, days of survival, shoot dried weight and root dried weight were also evaluated. Shoot height was recorded from the root base to the tip of the longest leaf, excluding any dead portion. Root length was determined from the root -shoot junction to the tip of the longest root. The samples of plants were dried at $65^{\circ} \mathrm{C}$ for 3 days for dry weight measurements

Observation score of salinity injury of seedlings

Score 1: Normal growth, no leaves symptoms (highly tolerant);

Score 3: Nearly normal growth, but leaf tips or few leaves whitish and rolled (tolerance);

Score 5: Growth severely retarded; most leaves rolled; only a few are elongating (moderately tolerance)

Score 7: Complete cessation of growth; most leaves dry; some plants dying (sensitive)

Score 9: Almost plants dead or dying (highly sensitive).

\section{Genomic DNA Extraction and Simple Sequence Repeat Bioassay}

The seeds of the collected rice landraces were grown in container $(40 \times 50 \mathrm{~cm})$ at the experiment farm of PRC in August, 2015, 2-3 weeks after growing, a piece of young leaves of each rice landrace was collected at the early morning for DNA extraction. The method was done following the report of Linh et al [12]. In brief, the materials were kept in moist tissue paper in a pastic bag, kept away from sunlight and were frozen immediately in liquid nitrogen on the day of collection. They were used immediately, or frozen at $-20^{\circ} \mathrm{C}$ util required. Cetyl trimethy ammonium bromide (CTAB) method was applied for DNA extraction as a standard protocol: briefly, a $4.0 \mathrm{~g}$ of leaf sample was ground in liquid nitrogen using mortar and pestle pre-chilled to $-20^{\circ} \mathrm{C}$. Pulverized leaves were promptly transferred to a liquid nitrogen prechilled, $50 \mathrm{ml}$ falcon tube. The $2 \%$ of preheated $\left(65^{\circ} \mathrm{C}\right)$ CTAB buffer $(16 \mathrm{ml})$ containing $5 \% \mathrm{v} / \mathrm{v} \beta$-mercaptoethanol and $2 \%$ PVP were quickly added to the tube and stirred with a glass to mix. The tube was incubated at $65^{\circ} \mathrm{C}$ for 5 min with frequent swirling. An equal volume of chloroform: octanol (24:1) was added and the sample 
was centrifuged for not more than $5 \mathrm{~s}$ in a bench-top centrifuge (Biofuge 13, Heraeus) at room temperature to separate the phases. The supernatant was carefully decanted and transferred to a new tube. The above steps, beginning with the addition of chloroform/octanol (24:1) and ending with decanting of supernatant, were repeated twice. The supernatant was precipitated with $2 / 3$ volume of isopropanol. The precipitated nucleic acids were collected and washed twice with the buffer $(75 \%$ ethanol, $10 \mathrm{mM}$ ammonium acetate, TE). The pellets were air-dried and resuspended in TE. The dissolved nucleic acids were brought to $2 \mathrm{M} \mathrm{NaCL}$ and re-precipitated using 2 volumes of $70 \%$ ethanol. The tube was incubated at $65^{\circ} \mathrm{C}$ for for $5 \mathrm{~min}$ to dissolve genomic DNA, and Rnase was then added. The yield of DNA per $\mathrm{g}$ of leaf tissue extracted was measured using a UV-VIS Spectronic Genesys 5 (Milton Roy) spectrophotometer at $260 \mathrm{~nm}$. The purity of DNA was recorded by calculating the ratio of absorbance at $260 \mathrm{~nm}$ to that of $280 \mathrm{~nm}$.

\section{SSR scoring and analysis}

The SSR marker RM127 linked with QTL qSTR-4-CK was used to re-confirm the salinity tolerance ability in the selected rice landraces (salt tolerance). This marker was previously identified via the mapping QTL in the crossed population between high salinity tolerance of Chanh trui $\mathrm{x}$ Khang dan 18 in our previous studies $[2,13]$.

\section{Evaluation of salt tolerance on field condition}

Evaluation of salinity tolerance of rice landraces in this study was conducted following the method of IRRI [14]. Each plot of the experiments was $2 \mathrm{~m}$ x $5 \mathrm{~m}$. The plots were covered well at its bottom by nylon to prevent water penetration from other plots. The sandy soil was sterilized by HCL solution ( $0.5 \mathrm{M}$ concentration), then soaped by tap water, then dumped on each plot with depth $10 \mathrm{~cm}$. Rice seedlings of each landrace were then transplanted by hand with 30 plants per row, and 5 rows per landrace. Salt stress was imposed 15 days after transplanting (2-3 leaves per plants) by adding $\mathrm{NaCl}$ solution $\mathrm{pH}=5.0$. Salt solution was daily changed by one time per 2 days to maintain accurate $\mathrm{pH}$. Khang dan 18 was used as a susceptible variety as stated in our previous report [2].

Observation criteria based on the scores as following:

Score 1: highly tolerant landrace (HT)

Score 3: tolerance landrace $(\mathrm{T})$

Score 5: moderate tolerance landrace (MT)

Score 7: sensitive landrace (S)

Score 9: All most plants dead or dying

\section{Statistical analysis}

The data were analyzed using by Excel version 2007 and IRRISTAT 5.0 software. The molecular weights of the different allens were determined by Alpha Ease Fc 5.0 software. All alleles were scored manually and double-checked.

\section{Results}

\section{Evaluation of salt tolerance in the laboratory condition}

Generally, during the onset and development of salt stress within a plant salinity affects plants in many ways physiologically such as photosynthesis, protein synthesis and energy etc, which have probably reduced the growth and development of plants. Especially in the stage of vegetative growth, the plant height, shoot weight, number of tiller per plant, dry weight of roots, root elongation and number of day to survive are all significantly influenced by salinity. However, not all growth parameters are similarly affected by salinity [15]. In this experiment, 41 rice landraces were tested for their salinity tolerance at three levels of salinity, $0 \mathrm{dS} / \mathrm{m}, 6 \mathrm{dS} / \mathrm{m}$ and $16 \mathrm{dS} / \mathrm{m}(0 \mathrm{dS} / \mathrm{m}$ without salt imposed). 


\section{Survival days of seedlings}

There was a significant difference between the survival days of the rice seedlings among the tested rice landraces at salinization $\mathrm{EC}=16 \mathrm{dS} / \mathrm{m}$. The maximum survival days of Chanh trui (26 days) and Nep cuc (25 days) were observed, shown higher than the tolerance control Pokkali (21 days). Six landraces were endured by 20-21 days which were similar with the Pokkali were: Hom rau 1, Bau Hai Phong, Cuom dang 2, Hom rau 2, CM6, Cuom dang 1, respectively. Withstanding ranged 15-19 days was found in 9 landraces which showed slightly lower than the control Pokkali included: On, Nuoc man, Quang trang, Lua ngoi, Manh ghe, Lua su dang 1, Lua cham bien, Ngoi tia and Chiem cu. Duration of survival of the other landraces (22 landraces) showed similar with IR28 (sensitive variety) by around 8 days. All landraces were grown well in Yoshida solution after 35 days of transplanting, but only survived 29.6 days and 14.5 days on average in the solution added salt $\mathrm{EC}=6 \mathrm{dS} / \mathrm{m}$ and $\mathrm{EC}=16 \mathrm{dS} / \mathrm{m}$, respectively. As monitored in this experiment, the result showed that the magnitude of survival days of seedlings was inversely proportional to the applied dose of salinity.

\section{Growth parameters}

\section{Plant height}

Plant height of all rice landraces were reduced by salinity even at low salinity treatment $(\mathrm{EC}=6 \mathrm{dS} / \mathrm{m})$. The plant heights of all landraces after 3 weeks of salinization were significantly diminished to compare with the controls. The average plant height of all landraces at $\mathrm{EC}=6 \mathrm{dS} / \mathrm{m}$ were $21.41 \mathrm{~cm}$, in which Cuong dang 1 was shown the highest $(28.23 \mathrm{~cm})$, while IR28 was the lowest $(19.40 \mathrm{~cm})$. Most heights of landraces were reduced at $\mathrm{EC}=16 \mathrm{dS} / \mathrm{m}$ by $19.64 \mathrm{~cm}$ on average, except for Te cham, Chanh trui, Cuom dang 2, Lua ngoi, Hom rau 2, Cuom dang 1, Lua cham bien and Re trang, respectively. There was a negative correlation between salt dose application and plant height. It also found significant differences between landraces at the different salt levels. The results were consisted with some previous studies to assess effect of salinity on the growth and development of some modern rice varieties [15].

\section{Root length (RL)}

On average root length of all landraces at the salt concentration $\mathrm{EC}=16 \mathrm{dS} / \mathrm{m}$ was $9.37 \mathrm{~cm}$. There were 6 landraces exerting the highest root length that were similar with Pokkali (highly tolerant) by ranged about $9.77 \mathrm{~cm}$ were: Nep cuc, Nuoc man dang 1, CM6, Q5, Cuom dang 1 and Ngoi tia, whereas, 9 landraces showed their shoot length slightly lower than the control were: On, Bau Hai Phong, Nuoc man, Lua cham bien, Hom rau, Tam du, Re trang, Te tep and Nep chan. At lower salt concentration $\mathrm{EC}=6 \mathrm{dS} / \mathrm{m}$, the average of the landrace was about $11.76 \mathrm{~cm}$, of which, the highest root length was found in Hom rau $2(14.49 \mathrm{~cm})$, higher than the Pokkali $(13.13 \mathrm{~cm})$. The root length of Quang trang $(9.67 \mathrm{~cm})$ was the lowest to compare with other landraces.

\section{Root dry weight (RDW)}

RDW was found inversely related to the salt concentration. On average, over all landraces at $\mathrm{EC}=16 \mathrm{dS} / \mathrm{m}$, the root dry weight was $27.03 \mathrm{mg}$. In this experiment, Pokkali showed the highest root dry weight by $39.14 \mathrm{mg}$ to compare with the other landraces, except for Chanh trui $(40.33 \mathrm{mg})$ that higher than the Pokkali. Three landraces demonstrated their RDWs similar with the Pokkali were: Lua su dang 1, CM6 and Lua ven dang 1. It is noted that only two landraces, Nep quat and Ven do disclosed lower RDWs $(\approx 20.06 \mathrm{mg})$ than the IR28 $(25.75 \mathrm{mg})$, respectively. At the salt concentration $\mathrm{EC}=6 \mathrm{dS} / \mathrm{m}$, the average RDWs of the landrace were $29.56 \mathrm{mg}$, and varied from 26.0 to $31.0 \mathrm{mg}$.

\section{Shoot dry weight (SDW)}

The results of variance analysis showed SDWs of all landraces were significantly different among two levels of salinity treatments. The average SDWs of the landraces were $116.2 \mathrm{mg}$ at the 
salt concentration $\mathrm{EC}=6 \mathrm{dS} / \mathrm{mg}$ and were $93.63 \mathrm{mg}$ at $\mathrm{EC}=16 \mathrm{dS} / \mathrm{m}$, respectively. In this experiment, the high salinity tolerance Pokkali showed the highest SDW by $131.45 \mathrm{mg}$, which was significant difference with IR28 (59.34mg)-a sensitive control variety. SDWs of 4 landraces included Chiem rong, Chanh trui, Ven do and Nep cuc were shown similar with the SDWs' control.

\section{Salinity tolerance ability of the tested landraces}

As shown in Figure 1 and Table 2, there were 9 landraces included the sensitive control IR28, showing the sensitive symptom of salinity after 2 weeks of salinization ( 9 score). Thirteen landraces were monitored salinity tolerance ( 5 score), similar with the Pokkali were: Nuoc man, Lua su dang 1, Lua ven, Quang trang, Hom rau 1, Hom rau 2, Cuom dang 1, Chiem rong, Lua cham bien, Manh re, Chiem cu, Bau Hai phong and On landraces. Three landraces revealed high salinity tolerance were Chanh trui, Cuom dang 2 and Nep cuc (5 score). Also, 9 landraces were found survival after 3 weeks of salinity treatment were: On, Bau Hai phong, Lua ven dang 1, Pokkali, Manh ghe, Hom rau 2, Lua su dang 1, Cuom dang 1 and Chiem cu (7 score) (Figure 1).

Table 2. Screening salinity tolerance of rice in the laboratory condition

\begin{tabular}{|c|c|c|c|c|c|c|c|}
\hline No & Rice landrace & $\begin{array}{c}\text { ST } \\
\text { score }\end{array}$ & STA & No & Rice landrace & $\begin{array}{l}\text { ST } \\
\text { score }\end{array}$ & STA \\
\hline 1 & Bac thom 7 & 9 & $\mathrm{HS}$ & 22 & Re trang & 7 & $\mathrm{~S}$ \\
\hline 2 & Nuoc man Hue & 7 & $\mathrm{~S}$ & 23 & Nep quan & 9 & HS \\
\hline 3 & Nuoc man dang 1 & 5 & MT & 24 & Manh re & 5 & MT \\
\hline 4 & Hau trang & 7 & $\mathrm{~S}$ & 25 & Chiem cu & 5 & MT \\
\hline 5 & Lua do & 9 & $\mathrm{HS}$ & 26 & Bau Hai phong & 5 & MT \\
\hline 6 & Lua su dang 1 & 5 & MT & 27 & Nep chan & 7 & $\mathrm{~S}$ \\
\hline 7 & Lua ven dang 1 & 5 & MT & 28 & Te tep & 7 & $\mathrm{~S}$ \\
\hline 8 & Te cham & 7 & $\mathrm{~S}$ & 29 & On & 5 & MT \\
\hline 9 & Quang trang & 5 & MT & 30 & Du Thanh Hoa & 9 & $\mathrm{HS}$ \\
\hline 10 & Ven do & 9 & HS & 31 & Ven lun Thanh Hoa & 7 & $\mathrm{~S}$ \\
\hline 11 & Nuoc man Quang tri & 7 & $\mathrm{~S}$ & 32 & Tam dau & 9 & $\mathrm{HS}$ \\
\hline 12 & Lua ngoi & 7 & $\mathrm{~S}$ & 33 & Te thom Lao Cai & 9 & $\mathrm{HS}$ \\
\hline 13 & Lua cham & 9 & $\mathrm{HS}$ & 34 & Tam thom & 7 & $\mathrm{~S}$ \\
\hline 14 & Hom rau 1 & 5 & MT & 35 & Chiem tia chan & 9 & $\mathrm{HS}$ \\
\hline 15 & Hom rau 2 & 5 & MT & 36 & Du thom & 7 & $\mathrm{~S}$ \\
\hline 16 & Cuom dang 1 & 5 & MT & 37 & Loc Nghe An & 9 & $\mathrm{HS}$ \\
\hline 17 & Cuom dang 2 & 3 & $\mathrm{~T}$ & 38 & Tam nong & 7 & $\mathrm{~S}$ \\
\hline 18 & Chiem rong & 7 & $\mathrm{~S}$ & 39 & Nep rau & 9 & HS \\
\hline 19 & Ngoi tia & 5 & MT & 40 & Chanh trui & 3 & $\mathrm{~T}$ \\
\hline 20 & Nep ccc & 3 & $\mathrm{~T}$ & 41 & Khang dan 18 & 9 & $\mathrm{HS}$ \\
\hline \multirow[t]{2}{*}{21} & Lua cham bien & 5 & MT & 42 & $\begin{array}{l}\text { Pokkali (salt tolerance } \\
\text { control) }\end{array}$ & 3 & HT \\
\hline & & & & 43 & $\begin{array}{l}\text { IR28 (salt } \quad \text { sensitive } \\
\text { control) }\end{array}$ & 9 & $\mathrm{~S}$ \\
\hline
\end{tabular}

STS: salinity tolerance score; STA: Salinity tolerance ability; HT: High tolerance; T: tolerance; MT: moderate tolerance; S: sensitive. 


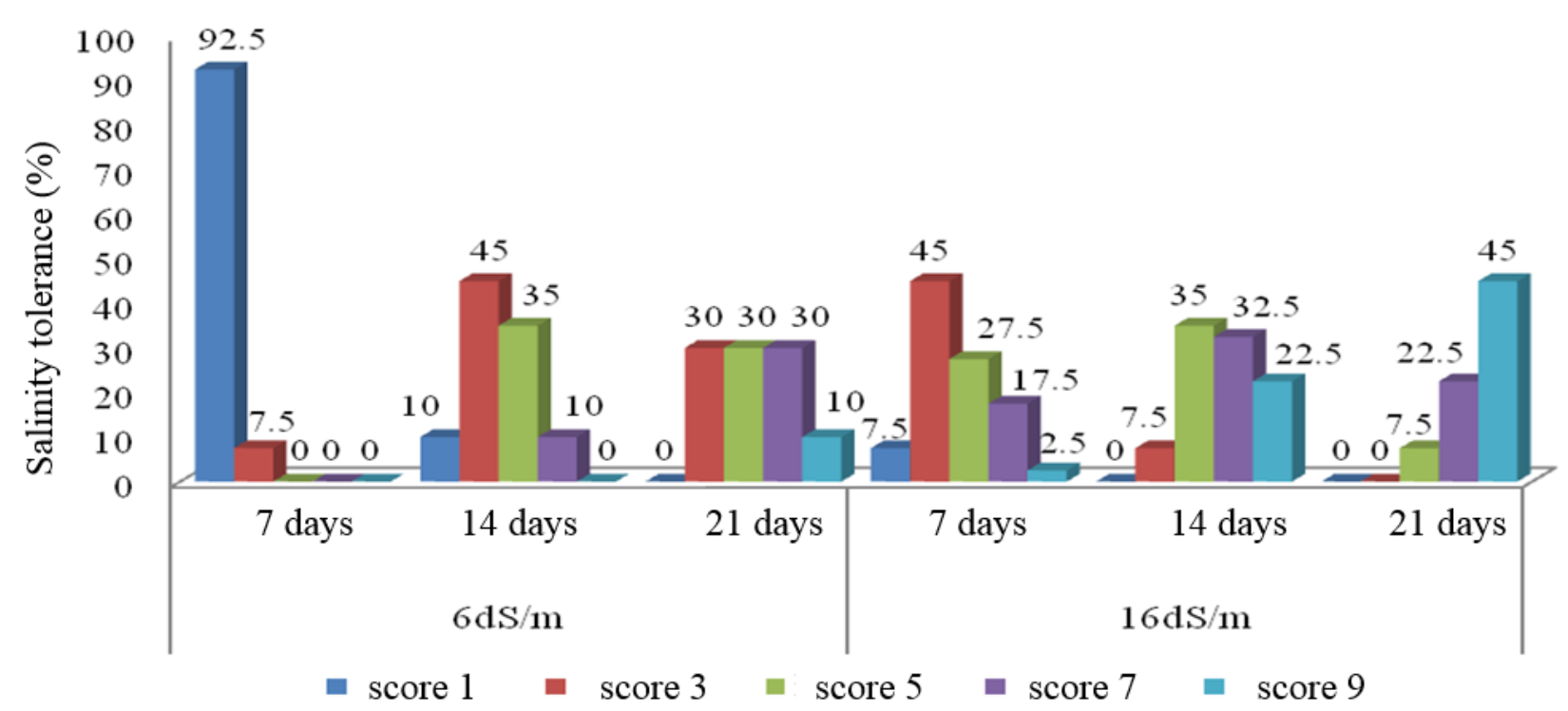

Figure 1. Salinity tolerance (\%) of rice landraces in Yoshida nutrient added NaCL with EC $=6 \mathrm{dS} / \mathrm{m}$ and $\mathrm{EC}=16 \mathrm{dS} / \mathrm{m}$

\section{Evaluation of salt tolerance in field condition}

According to the previous reports, rice growing areas in Vietnam, especially, the coastal areas of rice field have coped with salt water intrusion up to $0.6 \%[3,4,8]$. Therefore, in this study, the salinity solution was adjusted by $0.5 \%$ in each plots of experiment in the field condition. According to data shown in the Table 3, there have been 25 rice landraces showing salinity tolerance ability from T to MT. Among them, Nep cuc, Cuom dang 2 and Chanh chui revealed salt tolerance by 3 score, followed by 21 rice landraces ( 5 score): Nuoc man Hue, Nuoc man dang 1, Hau trang, Lua su dang 1, Lua ven dang 1, Te cham, Quang trang, Nuoc man Quang tri, Hom rau 1, Hom rau 2, Cuom dang 1, Chiem rong, Ngoi tia, Lua cham bien, Re trang, Manh re, Chiem cu, Bau Hai Phong, Te tep, On, Ven lun Thanh Hoa and Tam dau, respectively. Two landraces included Khang dan 18 (control) and Loc Nghe An revealed non-salinty tolerance by 9 score (Table 3). There have been 14 landraces that exhibited sensitive tolerance by 7 score were Bac thom 7, Lua do, Ven do, Lua ngoi, Lua cham, Nep quan, Nep chan, Du Thanh Hoa, Te thom Lao Cai, Tam thom, Chiem tia chan, Du thom, Tam nong and Nep rau, repectively.

Table 3. Evaluation of salt tolerance of the rice landraces on field condition

\begin{tabular}{|c|l|c|c|c|c|l|c|c|c|}
\hline No & \multicolumn{1}{|c|}{ Rice landrace } & STS & ST & $\begin{array}{c}\text { ST } \\
\text { allen }\end{array}$ & No & Rice landrace & STS & ST & $\begin{array}{c}\text { ST } \\
\text { allen }\end{array}$ \\
\hline 1 & Bac thom 7 & 7 & S & - & 22 & Re trang & 5 & MT & - \\
\hline 2 & Nuoc man Hue & 5 & MT & - & 23 & Nep quan & 7 & S & - \\
\hline 3 & Nuoc man dang 1 & 5 & MT & + & 24 & Manh re & 5 & MT & + \\
\hline 4 & Hau trang & 5 & MT & - & 25 & Chiem cu & 5 & MT & + \\
\hline 5 & Lua do & 7 & S & - & 26 & Bau Hai phong & 5 & MT & + \\
\hline 6 & Lua su dang 1 & 5 & MT & + & 27 & Nep chan & 7 & S & - \\
\hline 7 & Lua ven dang 1 & 5 & MT & + & 28 & Te tep & 5 & MT & - \\
\hline 8 & Te cham & 5 & MT & - & 29 & On & 5 & MT & - \\
\hline 9 & Quang trang & 5 & MT & - & 30 & Du Thanh Hoa & 7 & S & - \\
\hline 10 & Ven do & 7 & S & - & 31 & Ven lun Thanh Hoa & 5 & MT & - \\
\hline 11 & Nuoc man Quang tri & 5 & MT & - & 32 & Tam dau & 5 & MT & - \\
\hline 12 & Lua ngoi & 7 & S & - & 33 & Te thom Lao Cai & 7 & S & - \\
\hline 13 & Lua cham & 7 & S & - & 34 & Tam thom & 7 & S & - \\
\hline 14 & Hom rau 1 & 5 & MT & - & 35 & Chiem tia chan & 7 & S & - \\
\hline 15 & Hom rau 2 & 5 & MT & - & 36 & Du thom & 7 & S & - \\
\hline 16 & Cuom dang 1 & 5 & MT & + & 37 & Loc Nghe An & 9 & HS & - \\
\hline 17 & Cuom dang 2 & 3 & T & + & 38 & Tam nong & 7 & S & - \\
\hline
\end{tabular}




\begin{tabular}{|c|l|c|c|c|c|l|c|c|c|}
\hline No & \multicolumn{1}{|c|}{ Rice landrace } & STS & ST & $\begin{array}{c}\text { ST } \\
\text { allen }\end{array}$ & No & \multicolumn{1}{|c|}{ Rice landrace } & STS & ST & $\begin{array}{c}\text { ST } \\
\text { allen }\end{array}$ \\
\hline 18 & Chiem rong & 5 & MT & - & 39 & Nep rau & 7 & S & - \\
\hline 19 & Ngoi tia & 5 & MT & + & 40 & Chanh trui & 3 & T & + \\
\hline 20 & Nep cuc & 3 & T & + & 41 & Khang dan 18 & 9 & HS & - \\
\hline 21 & Lua cham bien & 5 & MT & + & & & & & \\
\hline
\end{tabular}

${ }^{(+)}$: Landrace carrying salinity tolerance allen; ${ }^{(-)}$: Landrace without salinity tolerance allen. STS: salinity tolerance score; STA: Salinity tolerance; HT: High tolerance; T: tolerance; MT: moderate tolerance;

S: sensitive.

\section{Identification QTL/gene involving the salinity tolerance of rice}

In this study, the SSR marker RM125 which tighly linked to $q S T R-4-C K-\mathrm{QTL} /$ gene salinity tolerance on the chomosome 4 of Chanh chui rice landrace was used to identify the involvement of the 15 selected rice landraces which showed salinity tolerance in both laboratory and field screenings.

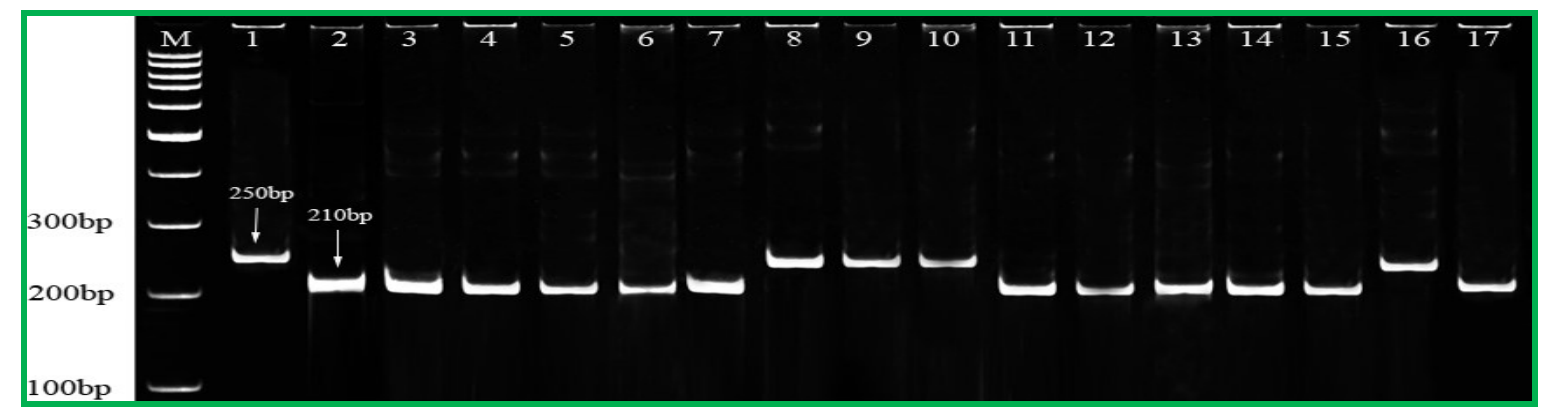

Figure 2. PCR products by using RM127; lane: 1. Khang dan 18 (sentitive control); 2. Chanh trui (tolerance control); 3. Cuom dang 2; 4. Nep cuc; 5. Nuoc man dang 1; 6. Lua su dang 1; 7. Lua ven dang $1 ; 8$. Quang trắng; 9 . Hom rau 1; 10. Hom rau 2; 11. Cuom dang 1; 12. Ngoi tia; 13. Lua cham bien; 14. Manh re; 15. Chiem cu; 16. On; 17. Bau Hai Phong

As shown on Figure 2, there have been 11 landraces including Cuom dang 2, Nep cuc, Nuoc man dang 1, Lua su dang 1, Lua ven dang 1, Cuom dang 1, Ngoi tia, Lua cham bien, Manh re, Chiem cu, Bau Hai Phong which showed DNA lane $\approx 210$ bp similar with the DNA lane of Chanh trui (Quoc et al., 2014). The results have demonstrated the rice landraces carried the salinity tolerance allen of QTL $q S T R-4-C K$. On contrary, there were appreared the DNA lanes with $\sim 250$ bp of the landraces Quang trang, Hom rau 1, Hom rau 2, On, and Khang dan (sensitive control landrace), which were different from the DNA of Chanh trui. Therefore, the salinity tolerance allens have not presented on those 4 landraces on the chromosome 4 . The results have given more confirmation of the salinity tolerance on both laboratory and field screening. Based on the obtained results of genotying, we have successfully identified the salinity tolerance allen on the chromosome 4 (Table 3). However, the rice landraces present ST allen but showed the different salinity tolerance ability such as: Chanh trui, Cuom dang 2 and Nep cuc to compare with Nuoc man dang 1, Lua su dang 1, Lua ven dang 1, Cuom dang 1, Ngoi tia, Lua cham bien, Manh re, Chiem cu, Bau Hai Phong. The different ST ability on those rice landraces may be explained that salinity tolerance has depended upon the background of each rice landrace and its origin.

\section{Discussion}

The results of the current study have indicated the effects of salinity at EC $=6 \mathrm{dS} / \mathrm{m}$ and $\mathrm{EC}=16 \mathrm{dS} / \mathrm{m}$ on the growth of 41 local rice landraces. The 41 landraces were collected from the different ecosystem areas and kept in PRC. Among them, 39 landraces were selected from the coastal provinces such as Thanh Hoa, Thai Binh, Nam Dinh and Quang Tri as shown in Table 1. Practically note that the landraces have been a long time cultivated in coastal areas where frequently affected with salt intrusion. According to the previous reports, rice growing areas in Vietnam, 
especially, the coastal areas of rice field have encountered with salt water intrusion up to $0.6 \%[3,4$, 8]. Therefore, the design of field plot was adjusted by $0.5 \%$ salt concentration.

In bioassay, two levels of salinity treatment at $\mathrm{EC}=6 \mathrm{dS} / \mathrm{m}$ and $\mathrm{EC}=16 \mathrm{dS} / \mathrm{m}$ concentrations were designed to evaluate the detrimental influences of salt on the growth of the landraces. The growth parameters of the landraces included: plant height, lengths of shoot and root, and their dry weight were significantly reduced to compare with the controls even at the low salinity treatment $(\mathrm{EC}=6 \mathrm{dS} / \mathrm{m})$ and more seriously injury with increasing salinity. Salt injury symptoms were obviously visible in all plant growing in the levels of salt and manifesting different symptoms that depended on the landraces and their origins. The degree of injury was shown more serious in the highest salt concentration $(\mathrm{EC}=16 \mathrm{dS} / \mathrm{m})$. The visual observation was as whitist spots along the middle if the leaves blade, and young and middle leaves of the landraces were rolled, droopy and withered away within 2-3 days of salt imposition. However, some landraces showed high tolerance at all levels of salinity treatments such as Chanh trui and Nep cuc, higher than the salt tolerance control Pokkali by 5-6 days of survivals. Also, plant height, shoot length, root length, dry weight of roots and shoots were significantly reduced in all landraces when increasing salinity treatment, the magnitude of reduction has shown variable between the different landraces.

Roots are in direct contact with the surrouding solution. Hence, they are first to encounter the saline medium and are potentially the first site of damage or of defense under salt stress. Roots growth of rice in this experiment were significantly suppressed by high concentrations of NaCL. The results were agreed to some previous reports in rice as well as some other crops $[15,16]$. It may explain that salinity affected final cell size and as well as rate of cell production [17] and caused the roots to be shortened. Nevertheless, the results have not consisted with the study of Cramer et al [18] who demonstrated that roots were less sensitive to salt than shoots. This disagreement may be involved in the methodology, particularly whether the experiment related to transplanting, or application of salt solution to the direct plants. Specifically in case of rice, after transplanting the previous roots were declined and new roots started growing and developing to support the plant [19].

\section{Conclusions}

In conclusions, 15 out of 41 local Vietnamese rice landraces in this study have shown salinity tolerance ranged from MS to $\mathrm{T}$ tolerance, of which Chanh trui, Cuom dang 2 and Nep cuc demonstrated the highest salinity tolerance ( 3 score) in both laboratory and field screenings. Thirthteen landraces have revealed feeble salinity tolerance ( 7 score), whereas, 10 landraces indicated sensitive to salinity similar with IR28. By use of RM127 marker linked with salinity tolerance QTL located on the chromosome 4, we have identified 11 landraces carrying allen of salinity tolerance QTL. This study has provided useful information on the Vietnamese rice landraces for further rice breeding to deal with the climate change.

\section{References}

[1] N.T. Lang et al., Genetic diversity of salt tolerance rice landraces in Vietnam, J. Plant Bred.Crop Sci. 1 (2009) 230-243.

[2] L.H. Anh et al., Identification of QTLs tolerance to salinity in rice (Oryza sative L.), International Journal of Development Research. 4 (2015) 2113-2118.

[3] L.T. Nghia, L.T.T. Trang, Study on salt tolerance and genetic diversity of some local Vietnamese rice varieties, J. Agric Rural Dev. 12 (2012) 11-26.

[4] L.H. Linh et al., Molecular breeding to improve salt tolerance of rice (Oryza sativa L.) in the red river delta of Vietnam, International Journal of Plant Genomics. 2012 (2012) Article ID 949038.

[5] R. Munns, Genes and salt tolerance: bringing them together, New Phytologist. 167(3) (2005) 645-663. 
[6] S. Bado et al., Protocol for screening for salt tolerance in rice, in: S. Bado et al (Eds.), Protocols for pre-field screening of mutants for salt tolerance in rice, wheat and barley, Springer International Publishing AG., Switzerland, 2016, pp.21-31.

[7] P. Schmidt-Thome et al., Climate change in Vietnam, in: P. Schmidt-Thome et al (Eds.), Climate change adaptation measures in Vietnam Development and Implementation. Spinger International Publishing., Cham Heidelberg New York Dordredcht London, 2015, pp. 7-14.

[8] L.H. Ham, T.D. Khanh, Applying molecular breeding for rice improvement, Agric Pub, Vietnam, 2015, pp.25-40.

[9] MARD-Ministry of Agricultural and Rural Development, Workshop on drought, salinity intrusion affected provinces in Cuu Long river delta; held in Can Tho city, Feb 17, 2016.

[10] L. Zeng, M.C. Shannon, C.M. Grieve, Evaluation of salt tolerance in rice genotypes by multiple agronomic parameters, Euphytica. 127 (2002) 235-245.

[11] IRRI-International Rice Research Institute, Screening rice for salinity tolerance, IRRI Discussion paper Series, 1997.

[12] T.H. Linh et al., Improving submergence tolerance of Vietnamese rice cultivar by molecular breeding, Journal of Plant Breeding and Genetics. 1(3) (2013) 157-168.

[13] N.KQuoc, H.T.Hue, L.T.Nghia, Mapping salt tolerance QTL of rice, J. Agric. Rural Dev. 22 (2014) 3-9.

[14] Standard Evaluation System for rice (SES), International Rice Research Institute - IRRI (2002), Metro Manila, Philippines.

[15] M.Z. Alam et al., Effect of salinity on growth of some modern rice cultivars, Journal of Agronomy. 3 (2004) 1-10.

[16] A.R. Dadkhad, W.S. Stewart, H. Griffiths, Effects of salinity on yield and root quality of sugar beet (Beta vulgaris L.). J. Exp. Bot. 52 (2001) 31.

[17] H.B. Azaizeh, B. Gunse, E. Steudle, Effects of NaCL and $\mathrm{CaCl} 2$ on water transport across root cells of maize (Zea mays L) seedling, Plant Physiol. 99 (1992) 886-894.

[18] G.R. Cramer, E. Epstein, A. Lauchli, Effects of sodium, postassium and calcium on salt stressed barley. II. Elemental analysis, Physiol Planta. 82 (1991) 197-202.

[19] S. Yoshida, Salinity, In: Fundamentals of rice production, IRRI, Philippines, 1981, pp. 30-39. 